\title{
Organization of teaching of undergraduates in the IT
}

\author{
Maxim Sergievskiy ${ }^{1,2, *}$ and Konstantin Zajtsev $^{1}$ \\ ${ }^{1}$ National Research Nuclear University MEPhI, Moscow, Russia \\ ${ }^{2}$ Moscow Technological Institute, 199334, Moscow, Russia
}

\begin{abstract}
Recently considerable attention is paid to Russia the problem of competitiveness of Russian education, including the quality of training programs, strengthen human resource capacity of universities and improving their research. This work is devoted to one of the most acute problems of improving the quality of education: improving the content of training programs and guidelines for their implementation in the field of information technologies based on the experience of universities - the leaders of the world rankings. Describes an example of the formation of the master's program in the field of IT.
\end{abstract}

\section{Introduction}

Competitiveness of education is one of the key factors determining innovative activity of the modern state. Successful universities are "engine rooms" of creation, preservation and development of innovations and technologies, while the pace and depth of the innovation largely determine the economic and political weight of the country. History shows that those countries supporting and encouraging innovations have a more dynamic economic.

The annual turnover of innovative technologies and science-intensive products is now about 3-4 trillion dollars, according to Russian Academy of Sciences [1]. Russia currently accounts for only $0.2 \%$ of world trade, while the share of high-tech products does not exceed 4$5 \%$. Information and telecommunication technologies are one of the widely-shared priorities of global development, and the need for talent in this sector is growing (including in Russia) [2].

The majority of Russian universities, in accordance with the Bologna agreement, offer two-stage learnings system (Bachelor and MS), and information and telecommunications field is certainly not an exception. There are several approaches to the definition of the content of the IT education based on occupational standards in the field of information technology [3] which allows to take into the account perspective directions for development of information and communication technologies in the world. This note discusses one of the approaches of organizing educational process in this field. As an example we use one of the most common subject - Mathematics and Informatics.

One could assume that the program and the quality of education in Russia should conform to the world's highest standards, although in reality there is a considerable lag. From this prospective it clearly makes sense to employ the experience/practices of MS programs of the leading international universities. We think that two main trends create the foundation of their success:

- First is to treat education as the key link to scientific and technological development of the society, as well as humanitarian development.

- The second approach to consider education as a services for students and the economy.

The above trends shouldn't necessarily be mutually exclusive, but a clear priority for one of them determines the directions of development of education and its quality. Note that in many developed countries such as USA, UK, France, Japan, the priority in education is given the first trend, which largely provides a sufficiently harmonious development of education in the leading universities of those countries. However, this trend might have a certain side effects [4]: while "declaring a priority to increase the value of applied knowledge demanded by the knowledge-intense industries and economy in general, it could encourage stagnation of fundamental knowledge. The government programs encourage universities to create new technologies, but do not necessarily equally incentives the creation of new theories and the broad development of science in general."

The second trend is an approach to education - to services, is promoted by the initiators of the Bologna process in education. The potential side effects of this approach are: potential oversupply of professionals in the most prestigious fields at a certain period, the bureaucratization of higher education and potential deterioration of quality. This trend could lead to the reduction of funding of education, excessive formalization of the learning processes, introduction of complex regulatory bodies, both at the levels of state ministries and agencies, as well as at the level of

Corresponding author: sermax@yandex.ru 
universities that have not previously been a characteristic of Russian education system

\section{Ranking of the universities}

The selection of international universities for the purpose of this analysis and educational was conducted based on the three well-known ratings, suggested by the Russian Ministry of Education and Science - ARWU, THE and QS

\subsection{ARWU ranking}

The ARWU ranking system (Academic Ranking of World Universities) is designed in the Shanghai Jiao Tong University. In order to determine the level of educational standards we take two of the five subject areas of this rating: Natural Sciences and Mathematics, Engineering/Technology and Computer Science. To determine the rating for each institution four main criteria are used: quality of education; quality of teaching; academic level; academic efficiency. The list of the top universities, in accordance with the ARWU ranking is presented on the website [5].

\subsection{THE ranking}

THE ratings, according to the authors [6], presents one of the most comprehensive studies in this field. In the latest edition of the ranking released in 2011, is used thirteen parameters aggregated into five categories: industry income - innovation, teaching - learning environment, research - volume, income and reputation - research influence, international collaboration - staff and students.

\subsection{QS ranking}

QS World University Rankings suggest the ranking of the best universities in the world presented by the British consulting company Quacquarelli Symonds. The level of universities is assessed on the basis of the data describing the activity of educational institutions, including information about the citation index of Scopus database, and data from global expert surveys of the representatives of the international academic community and employers. The authors of this rating specifically emphasize that the volatility of the universities in the ranking is considerably lower than in the majority of other similar ratings, suggesting reliability and quality of the methodology used. Note that QS provides individual ratings for different geographical areas and field of studies. On the QS website [7] a special rating for Computer Science \& Information Systems study field is presented.

Here we aggregate all three key rating systems described above, in the attempt to create a league table for Information Technology universities. Firstly we structure the rating from the three providers mentioned above using a 100-point system. On the second stage we weight the ratings by the assigned value to each of them
[8]. Because this study has used only widely-recognized rankings (ARWU, THE and QS) we assign each rank an equal value for our aggregation purposes. The results of our aggregation are presented in the Table 1.

The analysis of MS (Master's Degree) programs of the leading IT universities in the world brings us to the following conclusions:

1. The duration of MS programs is on average one to two years. There is usually an option combine

Table 1. The ranking of the universities a work and a study, but in that case the duration of the program can be extended.

\begin{tabular}{|l|l|}
\hline \multicolumn{1}{|c|}{ University } & \multicolumn{1}{|c|}{ Rating } \\
\hline Massachusetts Institute of Technology & 100,00 \\
Stanford University & 97,84 \\
University of California, Berkeley & 93,23 \\
University of Oxford & 91,12 \\
Carnegie Mellon University & 87,24 \\
University of Cambridge & 84,15 \\
Princeton University & 81,88 \\
Harvard University & 77,60 \\
University of Toronto & 76,83 \\
Nanyang Technological University & 70,11 \\
University of Hong Kong & 69,39 \\
National University of Singapore & 67,23 \\
The Hong Kong University of Science & 65,46 \\
and Technology & \\
ÉcolePolytechniqueFédérale de Lausanne & 62,11 \\
The University of Tokyo & 62,98 \\
Australian National University & 61,76 \\
University of Edinburgh & 60,54 \\
University of California, Los Angeles & 60,02 \\
Imperial College London & 57,33 \\
The University of Tokyo & 56,63 \\
Georgia Institute of Technology & 55,52 \\
Cornell University & 48,00 \\
Technion Israel Institute of Technology & 45,74 \\
The University of Sydney & 39,96 \\
Liverpool John Moors University & 32,81 \\
\hline
\end{tabular}

2. There are usually two different types of MS programs: business career oriented and focused on science.

3. From the early stages students are encouraged to work with professional literature and Internet resources which allows to broaden the knowledge. It should be noted that independent projects of students are supervised by the faculty.

4. Each student has a supervisor and/or mentor, who helps to tailor training courses and build a path to a qualification work.

5. In the process of study students take 8 to 12 courses. The majority of subjects are chosen directly by the student. On the advanced stages students work on complex case studies both in the campus and directly in the industry.

6. Three or four disciplines usually are set up as a basement for a selected MS program and sometimes contain material previously familiar bachelor. Below is a list of basic disciplines for the master program "Computer Science" at the Oxford University[9]: Functional Programming

Object-Oriented Programming 


\section{Concurrent Programming \\ Concurrency}

\section{Introduction to Specification}

Foundations of Computer Science

It is worth noting that those courses which were covered at a Bachelor's stage are covering more advanced levels within the MS programs. Basic studied disciplines quite often are statutory. They are studied at the earlier stages and help to form the basement for future courses.

7. The disciplines studied in the following semesters are more specialized (for example: Data centers", "Software systems design", "Cloud computing") and reveal the direction the student will focus on. The selection of study is primarily determined by professional interests of a particular student. The set of disciplines below, taken from the MS program in "Information Sciences and Intelligent Systems" is one of the leading universities in Italy CA-Foscari in Venice [10]:

\section{Advanced Databases Compilers \\ Distributed Systems \\ Information Theory \\ Mathematical Logic \\ Numerical Algorithms \\ Artificial Intelligence \\ Data and Web Mining \\ High Performance Computing \\ Multimedia Systems}

8. There are three basic types of classes: lectures, seminars and laboratory work. One of the additional forms is the case-study, which is similar to a seminar, but, unlike it, gives students an opportunity to Express their views on a given topic or subject and participate in a discussion on an equal terms with colleagues and professors.

9. For many courses, and from the very beginning of study, there are mandatory group or individual projects. Substantial time is allocated substantial time for this projects.

10. To complete an MS program, students must earn a certain number of credits or points during both years of study. A 100-point system of results assessment involves continuous monitoring of student's performance during the term. This is done vie mini-tests, reference checks, homework assignments, essays, reports on laboratory work, attendance, and formal examinations

11. Any MS program ends with presentation and assessment of qualification work, which may be closely correlated to a real-life project for those students focused on the future work in the industry. Qualification work usually performed for 3-6 months, which are often free from other courses.

12. In case a student is focused on future research career, usually there is a special course explaining rules of work with scientific information, preparation of research publications and qualification works.

\section{MS programs in Russia}

MS programs should be tailored firstly to the market demand for certain groups of specialists, and secondly to target training students for independent research. Therefore, it is fair to assume that the training of masters unlike bachelors requires a different approach focused primarily on the needs of the economy. It is natural to assume that fundamental knowledge base has been already built by students at the previous stage of study (bachelor or specialist). Since participants of MS programs are usually mature in professional and personal sense with basic knowledge in programming, basic sections of discrete mathematics, databases, optimization techniques and probability theory.

The emphasis of MS programs is on obtaining a deeper knowledge and new expertise in a more narrow fields. Actual direction of study and sometimes even specific forms of training and practice are often agreed with future employers. The current educational standards leaves room for such approach as a mandatory part of the curriculum of masters is relatively modest, while the variable part gives enough room in the selection of disciplines. In addition, practical training allows students to adapt to the needs of a particular organization and gain experience by solving real problems and participating in various projects. In other words, graduates from MS programs should be ready to work in the industry or to start research career in a University. Depending on the initial arrangement a student can stay for a mandatory 3-6 month practice in a chosen organization after graduating with the MS degree.

At the same time, graduates should be free in their choice of employment in the medium term. Therefore, their compensation profiles should not be disadvantageous to international standards in the chosen field.

Thus, MS programs in Russia and leading Western countries are reasonably comparable, with an exception of minor details. Undergraduates in the learning process gain additional competence in the selected area, participate in research projects and in teaching practice. Leaving teaching activities of graduate students aside, let's take a closer look at "Applied mathematics and Informatics" MS program at the State Research University MEPhI. Required disciplines for this area includes the following courses: discrete and mathematical models; modern problems of applied mathematics and informatics, modern computing technologies, evolution and methodology of applied mathematics and informatics. The elective part of the curriculum is described in this note on the example of "Enterprise Application Integration" program and is relevant to many large enterprises. It makes sense to link the course to a prechosen computer platforms and particular software products. In our case, the industry partners were using Java platforms and supporting products from IBM, Oracle, and SAP. Following comprehensive consultations with the prospective employer of future students seven disciplines below were added to the four basic ones (see Table 2). 
Table 2. The list of disciplines

\begin{tabular}{|c|c|c|}
\hline №№ & Educational discipline & Module \\
\hline 1. & Informational system design & $\begin{array}{l}\text { Module 1. Development and management of requirements } \\
\text { Module 2. Modeling, UML diagrams } \\
\text { Module 3. The modeling of business processes }\end{array}$ \\
\hline 2. & $\begin{array}{l}\text { Principles of UNIX system } \\
\text { organization }\end{array}$ & $\begin{array}{l}\text { Module 1. Principles of organization of UNIX systems } \\
\text { Module 2. Operating system AIX } \\
\text { Module 3. Operating system HP-UX }\end{array}$ \\
\hline 3. & Information security & $\begin{array}{l}\text { Module } 1 \text {. Technology to solve the problem of confidentiality of information } \\
\text { Module } 2 \text {. Technology integrity of information } \\
\text { Module } 3 \text {. Technologies of control the authenticity of information } \\
\text { Module } 4 \text {. Methods of auditing and authentication }\end{array}$ \\
\hline 4. & $\begin{array}{l}\text { Service-oriented architecture } \\
\text { applications }\end{array}$ & $\begin{array}{l}\text { Module } 1 \text { Application architecture SOA } \\
\text { Module 2. SOA lifecycle } \\
\text { Module 3. Protecting Web services with WebSphere Data Power SOA } \\
\text { Appliances }\end{array}$ \\
\hline 5. & Standards of software integration & $\begin{array}{l}\text { Module 1. Integration patterns } \\
\text { Module 2. Basic technology XML/XSLT } \\
\text { Module 3. IBM Web Sphere Application Server }\end{array}$ \\
\hline 6. & $\begin{array}{l}\text { Integration of applications based } \\
\text { on message queues }\end{array}$ & $\begin{array}{l}\text { Module 1. System message queuing WebSphere MQ } \\
\text { Module 2. WebSphere Message Broker } \\
\text { Module 3. Messaging Oriented Middle Ware }\end{array}$ \\
\hline 7. & $\begin{array}{c}\text { Databases and systems on their } \\
\text { base }\end{array}$ & $\begin{array}{l}\text { Module 1. Data warehouse } \\
\text { Module 2. Oracle DB. Programming in Oracle environment } \\
\text { Module 3. System customer relationship management (CRM) } \\
\text { Module 4. Integrated SAP ERP solution }\end{array}$ \\
\hline
\end{tabular}

Each of the special disciplines is divided into modules, with each can be led by different professors. All courses have integrated cycles of laboratory works (4- 8 projects in each course), which by agreement can be performed in the office of a selected enterprise. Practice projects are performed in close cooperation with a selected enterprise and involve involvement of students in the development and launch of a specific project.

\section{Conclusion}

Comparative analysis of MS programs of the leading international universities and the best Russian universities, showed that with a broadly similar approach there are certain differences driven by both internal and external to universities reasons. MS programs at the leading Western universities are focused, primarily, on identifying and leveraging personal interests and strength of each individual, developing the ability to learn independently and supporting skills to conduct research and to participate in innovative projects.

With regard to the organization of study, the accumulated knowledge on the Russian education practices is still not enough to make definitive conclusions. However already now we could highlight certain external barriers related both to interactions with the sate (a dominant level of state financing and comprehensive reporting as a consequence), and business (the lack of high-tech industries, which are to act as a providers of joint playing fields for business and research institutes and universities). All the above does not allow adequately motivate employers, graduates and teachers.

It is paramount that in order to compete with the leading universities, Russia institutes should be at least on par with regards to comprehensiveness of educational programs. Provided rigorous supervision and assessment of the level of knowledge of students, comprehensive selection and certain reorganization of educational process in the Russian universities, it looks feasible to significantly raise the level.

In general, the transition towards a two-stage system of education in the field of IT has certain advantages (such as the ability to compare the quality of the educational process in different universities), and disadvantages:

- relatively small number of meaningful IT projects carried out by domestic scholars and engineering in Russia;

- the lack of qualified bachelors who wish to take MS programs at the leading Russian research universities; 
- a scarcity of educated personnel involved in a real life projects and able at to lead quality programs

in the rapidly evolving IT world;

- lack of interest from enterprises in investing in highly qualified specialists and raising them from the university.

In addition to purely educational factors success increase in competitiveness of the Russian universities is confronted by social, economic and political factors. Whether the country will be able to revert shrinkage of its own population, avoiding excessive centralization of the management system at all levels, bring education of talented students and children from well-to-do families back to Russia, will determine the success of education reform and further development of Russia in general.

\section{References}

1. A. Risina, Young Scientist, 5, 207-210 ( 2012)

2. Final analytical report: Prospective fields for development of the Russian IT sector (Long-term technological forecast of the Russian IT sector) (2007)
3. Professional Standards in the IT Industry, KIT, (2008)

4. S. Kostyukevich, AlmaMater, 4, 11-19 (2013)

5. Academic Ranking of World Universities in Computer Science $\quad-\quad 2015$ http://www.shanghairanking.com/SubjectCS2015.ht $\mathrm{ml}$

6. Times Higher Education World University Rankings' Engineering and Technology https://www.timeshighereducation.com/worlduniversity-rankings/2015/subject-ranking/ engineering-and-IT

7. QS World University Rankings http://www.topuniversities.com/universityrankings/university-subject-rankings/2015

8. M. Sergievskiy, K. Zajtsev, AlmaMater, 5, 62-66 (2014)

9. Site of University of Oxword http://www.cs.ox.ac.uk/admissions/grad/Taught_mo dules

10. Site of CA-Foscari in Venice http://www.unive.it/nqcontent.cfm?a_id=158105 